\title{
Pengaruh Anchoring dalam Penilaian Kinerja: Sebuah Studi Eksperimen Kuasi dengan Variabel Tergantung Penilaian Task Performance
}

\author{
Fityan Ayu ${ }^{1}$ \& Rahmat Hidayat ${ }^{2}$ \\ Fakultas Psikologi Universitas Gadjah Mada
}

\begin{abstract}
This study aimed to examine the effects of anchoring in task performance appraisal. It was hypothesized that there would be difference score in measuring task performance with high anchoring and low anchoring methods. High anchoring method was predicted to show higher scores rather than using low anchoring method. Participants were 117 post-graduate students of a university. They were assigned in two groups. The first group $(\mathrm{N}=70)$ was instructed to rate an employee from lower to higher score (high anchoring method), while the second group ( $\mathrm{N}=47$ ) was instructed to rate the employee from higher to lower score (low anchoring method). Result of independent sample T-test showed that anchoring method had no significant effect on task performance appraisal $(t=-0.918 ; d f=1 ; p>0.05)$. Factors which might be affecting this result are discussed.
\end{abstract}

Keywords: anchoring; appraisal; performance; post-graduate students; quasiexperimental study; task performance

Abstrak. Penelitian ini bertujuan untuk menguji pengaruh anchoring dalam penilaian kerja. Hipotesis penelitian ini yaitu ada perbedaan skor pada penilaian kerja dengan anchoring tinggi dan anchoring rendah. Anchoring tinggi diprediksikan memiliki skor yang lebih tinggi daripada anchoring rendah. Partisipan merupakan 117 mahasiwa pascasarjana. Partisipan ditugaskan dalam dua kelompok. Kelompok pertama $(N=70)$ diinstruksikan untuk menilai karyawan dari skor yang lebih rendah ke skor yang lebih tinggi (anchoring tinggi), sementara itu kelompok kedua $(N=74)$ diinstruksikan untuk menilai karyawan dari skor yang lebih tinggi ke skor yang lebih rendah (anchoring rendah). Hasil independent sample T-test menunjukkan anchoring tidak berpengaruh signifikan pada penilaian kinerja $(t=-0,918 ; d f=1 ; p>0,05)$. Faktor yang memengaruhi hasil ini akan dibahas.

Kata kunci: anchoring; mahasiswa pascasarjana; penilaian performansi; tugas performansi

Kinerja adalah hasil kerja berdasarkan kualitas dan kuantitas yang dicapai oleh

${ }^{1}$ Korespondensi dapat dilakukan melalui: fityanayu@gmail.com

2 Atau melalui r.hidayat@ugm.ac.id karyawan dalam melaksanakan tugasnya sesuai dengan tanggung jawab yang diberikan kepadanya (Mangkunegara, 2003). Kesuksesan suatu organisasi dapat dilihat pada kemampuannya dalam mengelola kinerja karyawan secara efektif 
dan efisien. Dimana bagian terpenting dalam pengelolaan kinerja pegawai terdapat dalam penilaian kinerja. Penilaian kinerja atau performance appraisal adalah suatu proses untuk mengetahui, mengevaluasi, dan mengukur kinerja semua karyawan dalam suatu organisasi atau perusahaan.

Dalam performansi kinerja terdapat beberapa aspek penting yang dinilai yaitu task performance, contextual performance, adaptive behavior, dan counterproductive. Task performance dapat didefinisikan sebagai efektivitas karyawan dalam melakukan kegiatan yang berkontribusi terhadap inti organisasi misalnya menyelesaikan tugas-tugas pekerjaan, kuantitas kerja, kualitas kerja, keterampilan kerja, pengetahuan pekerjaan, menjaga pengetahuan agar tetap up-to-date, bekerja secara akurat dan rapi. Contextual performance atau kinerja kontekstual dapat didefinisikan sebagai perilaku individu yang mendukung organisasi, lingkungan sosial, dan psikologis. Seperti perilaku yang melampaui tujuan kerja formal yang ditentukan, seperti mengambil tugas ekstra, menunjukkan inisiatif, antusiasme, perhatian terhadap tugas, motivasi, dedikasi, kreativitas, kerja sama, dan lainlain.

Adaptive behavior atau kinerja adaptif didefinisikan sebagai sejauh mana seorang individu menyesuaikan dengan perubahan dalam sistem kerja atau peran pekerjaan, misalnya, pemecahan masalah secara kreatif, berurusan dengan hal pasti atau tak terduga dalam situasi bekerja, belajar tugas baru, teknologi, dan prosedur, dan beradaptasi dengan individu lain, lingkungan fisik atau budaya dan lainnya. Sedangkan counterproductive work behavior didefinisikan sebagai perilaku yang merugikan kesejahteraan organisasi, contohnya seperti absensi, terlambat datang kerja, substansi penyalahgunaan, berkelahi atau berdebat dengan rekan kerja (Murphy, 1989).

Pengelolaan kinerja akan berjalan secara efektif ketika sistem penilaian kinerja berjalan dengan benar tanpa adanya bias yang terjadi. Setiap perusahaan pasti memiliki sistem penilaian kinerja yang berbeda-beda. Penilaian kinerja merupakan deskripsi sistematik, formal, dan evaluatif terhadap kualitas pekerjaan yang memiliki standar tertentu mengenai kelebihan serta kekurangan karyawan secara individu maupun kelompok, hal tersebut merupakan fungsi yang penting bagi personalia dan manajemen sumber daya manusia dalam perusahaan (Dessler, 2003; Riggio, 2003).

Penilaian kinerja dapat dilakukan oleh atasan, rekan kerja, bawahan, dan diri sendiri. Namun dalam penilaian kinerja ini seringkali terjadi bias yang menyebabkan adanya perbedaan dalam hasil evaluasi kinerja walaupun karyawan yang dinilai adalah orang yang sama. Hal tersebut timbul dikarenakan adanya pandangan yang berbeda mengenai orang lain, di mana pandangan tersebut dapat dipengaruhi oleh faktor ras, suku bangsa, jenis kelamin, hubungan interpersonal antara penilai dan karyawan yang dinilai, rasa suka dan tidak suka yang cenderung subjektif. Apabila pandangan-pandangan tersebut digunakan dalam proses penilaian kinerja maka akan membuat hasil evaluasi atau penilaian kinerja yang tidak valid.

Dalam pelaksanaan penilaian prestasi kerja ada beberapa masalah potensial yang perlu diperhatikan penilaian karena memengaruhi kualitas penilaian, menurut Werther dan Davis 
(1996) yaitu hallo effect, liniency effect dan severity effect, assimilation dan differential effect, first impression error, serta recency effect.

Kondrasuk (2011) menyatakan penilaian kinerja merupakan area yang paling bermasalah bagi sumber daya manusia dan area yang paling dihindari atau dibenci oleh manajer dan departemen sumber daya manusia. Sebagian besar karyawan merasa tidak nyaman dan tidak puas dengan proses penilaian kinerja (Kreitner \& Kinicki, 2011). Terdapat alasan filosofis dan empiris mengenai validitas dan keadilan penilaian kinerja yang memengaruhi akurasi dan bias dalam suatu penilaian kinerja (Bernardin \& Russell, 1998).

Menurut DeNisi dan Williams (1998) penilaian dari rater sering kali mengalami bias oleh sifat kognitif dan juga motivasional. Penelitian tentang penilaian kinerja akhir-akhir ini mulai memfokuskan pada masalah keadilan karena penilaian kinerja pada beberapa posisi tidak mampu mengukur secara objektif, hal tersebut disebabkan karena adanya keterbatasan kemampuan kognitif penilai maupun belum adanya kesepakatan tentang standar kinerja yang baik (Folger \& Konovsky, 1989).

Ada sejumlah alasan yang memungkinkan para penilai tidak memiliki hasil atau kesimpulan yang sama dalam memberi evaluasi pada satu individu (Tsui and Ohlott, 1988). Terdapat beberapa kesepakatan dari para penilai mengenai perbedaan dalam menilai seorang individu yaitu tingkat organisasi, pengetahuan kerja, pengolahan informasi, kecendrungan pengolahan informasi atau gaya rating, motivasi penilai, dan bias persepsi (Cardy and Dobbins, 1994; Harris, 1994; Tsui and Ohlott, 1988).
Berdasarkan pembahasan di atas, peneliti tertarik untuk mengetahui pengaruh anchoring terhadap hasil penilaian kinerja. Peneliti mengajukan hipotesis bahwa terdapat pengaruh anchoring dalam penilaian kinerja aspek task performance.

\section{Metode}

Variabel dependen dalam penelitian ini adalah penilaian kinerja pada aspek task performance, sedangkan variabel independen dalam penelitian ini adalah anchoring. Subjek dalam penelitian ini adalah mahasiswa Magister Manajemen Universitas X di Yogyakarta dan Jakarta. Subjek dari penelitian ini terdiri dari 204 booklet di mana 102 partisipan masuk ke dalam high anchoring dan 102 orang termasuk ke dalam low anchoring.

Setelah dikurangi dengan booklet yang tidak dikembalikan maka jumlah akhir booklet menjadi 146 booklet, di mana 87 orang termasuk ke dalam high anchoring yang terdiri dari 41 partisipan pria dan 46 partisipan wanita dan 59 orang termasuk ke dalam low anchoring yang terdiri dari 35 partisipan pria dan 24 partisipan wanita. Setelah itu dilakukan pula uji pemahaman. Uji pemahaman ini akan dilakukan dengan menyajikan lima pernyataan yang kemudian menjadi cek manipulasi. Hasil dari cek manipulasi ini yang akan menjadi pedoman peneliti untuk menentukan subjek yang telah diberi perlakuan akan lolos atau tidak ke dalam kelompok high anchoring maupun low anchoring. Kemudian diperoleh sebanyak 117 subjek yang lolos ke dalam kelompok high anchoring dan low anchoring di mana terdiri dari 70 subjek untuk kelompok high anchoring dan 47 subjek untuk kelompok low anchoring. 
Pada penelitian ini, metode pengumpulan data menggunakan metode kuantitatif dengan kuasi eksperimen. Pengumpulan data pada penelitian ini dilakukan dengan menggunakan booklet, yang secara langsung didistribusikan oleh peneliti kepada subjek eksperimen. Pembagian subjek eksperimen menjadi dua kelompok yaitu high anchoring dan low anchoring.

Menurut Murphy (1989), peran kinerja dapat didefinisikan efektivitas karyawan dalam melakukan kegiatan yang berkontribusi terhadap inti organisasi misalnya menyelesaikan tugastugas pekerjaan, kuantitas kerja, kualitas kerja, keterampilan kerja, pengetahuan pekerjaan, menjaga pengetahuan agar tetap up-to-date, bekerja secara akurat dan rapi. Alat ukur dalam penelitian ini menggunakan aspek dari task performance. Dalam penelitian ini peneliti di mana aspek tersebut memiliki empat dimensi yaitu kuantitas pekerjaan, kualitas pekerjaan, perencanaan kerja, dan pengambilan keputusan.

Metode analisis data dalam penelitian ini yaitu menggunakan T-test dengan menggunakan program komputer SPSS 18.0. Independent-sample T-test digunakan untuk membandingkan perbedaan skor antara high anchoring dan low anchoring pada dua kelompok eskperimen. Perbedaan skor di sini dapat dilhat dari hasil skor menilai kelompok high anchoring yang lebih tinggi dibandingkan dengan hasil skor dalam menilai kelompok low anchoring.

\section{Hasil}

Data dalam penelitian ini telah melalui uji normalitas dan uji homogenitas. Setelah itu dilakukan T-test dengan menggunakan program komputer SPSS 18.0. Hasil uji normalitas menggunakan Shapiro-Wilk menunjukkan bahwa data anchoring kelompok high anchoring berdistribusi normal $(p=0,068, p>0,05)$, dan sedangkan untuk kelompok low anchoring tidak berdistribusi normal $(p=0,020, p<$ 0,05). Sedangkan untuk hasil uji homogenitas menunjukkan bahwa varians data anchoring homogen $(p=0,222$, $p>0,05)$.

Hasil uji komparasi independent sample T-test menunjukkan adanya perbedaan skor yang tidak signifikan antara kelompok high anchoring dan low anchoring $(t=-0,918 ; d f=1 ; p>0,05)$. Oleh karena itu, hipotesis alternatif $\left(\mathrm{H}_{1}\right)$ dalam penelitian ini ditolak. Maka dapat disimpulkan bahwa anchoring tidak berpengaruh secara signifikan terhadap hasil penilaian kinerja pada aspek task performance. Hasil uji komparasi independent-sample T-test aitem kuantitas kerja pada kelompok high anchoring dan low anchoring menunjukkan bahwa terdapat perbedaan yang signifikan pada kuantitas pekerjaan $(t=-2,254 ; d f=1 ; p<$ 0,05). Hasil uji komparasi independentsample T-test aitem kuantitas kerja pada kelompok high anchoring dan low anchoring menunjukkan bahwa tidak terdapat perbedaan yang signifikan pada kuantitas pekerjaan $(t=-1,529 ; d f=1 ; p>$ $0,05)$.

Hasil uji komparasi independentsample T-test aitem kuantitas kerja pada kelompok high anchoring dan low anchoring menunjukkan bahwa tidak terdapat perbedaan yang signifikan pada kuantitas pekerjaan $(\mathrm{t}=0,115 ; \mathrm{df}=1 ; p>$ 0,05). Hasil uji komparasi independentsample $T$ Test aitem kuantitas kerja pada kelompok high anchoring dan low anchoring menunjukkan bahwa tidak 
terdapat perbedaan yang signifikan pada kuantitas pekerjaan $(t=1,178 ; d f=1 ; p>$ $0,05)$.

\section{Diskusi}

Hasil T-test dalam penelitian ini menunjukkan perbedaan skor pada kelompok eksperimen high anchoring dan kelompok eskperimen low anchoring yang tidak signifikan. Hal tersebut menunjukkan bahwa kelompok high anchoring tidak memiliki skor yang lebih tinggi dibanding dengan kelompok low anchoring. Menurut hasil penelitian tersebut, ada beberapa faktor yang memengaruhi adanya perbedaan hasil dalam menilai seorang karyawan yaitu terdapat dalam penelitian tentang penilaian kinerja.

Hal tersebut dikarenakan penilaian kinerja pada beberapa posisi tidak mampu mengukur secara objektif, disebabkan oleh keterbatasan kemampuan kognitif penilai maupun belum adanya kesepakatan tentang standar kinerja yang baik. Kemampuan kognitif disini terdiri dari beberapa hal, salah satunya mengenai anchoring (Folger \& Konovsky, 1989; deLeon \& Ewen, 1997). Terdapat sejumlah kesepakatan dari para penilai mengenai perbedaan dalam menilai seorang individu yaitu tingkat organisasi, pengetahuan kerja, pengolahan informasi, kecendrungan pengolahan informasi atau gaya rating, motivasi penilai, dan bias persepsi (Cardy and Dobbins, 1994; Harris, 1994; Tsui and Ohlott, 1988).

Hipotesis dari eksperimen ini tidak terbukti disebabkan karena penelitian ini dilaksanakan secara klasikal sehingga sangat memungkinkan setiap subjek saling berinteraksi satu sama lain. Hasil uji komparasi pada Tabel 8 yang menunjukkan bahwa hasil tidak signifikan dapat disebabkan karena instruksi yang telah dipaparkan peneliti di dalam booklet tidak terlalu diperhatikan sehingga para subjek tidak terpengaruh pada anchoring tersebut. Sama halnya dengan ketiga aspek dari task performance yang telah dipaparkan pada tabel 12 diatas. Hasil uji komparasi juga menunjukkan bahwa tidak ada perbedaan yang signifikan untuk aitem kualitas pekerjaan, perencanaan pekerjaan, dan pengambilan keputusan pada kelompok high anchoring dan low anchoring.

Anchoring merupakan bias kognitif yang ditemukan oleh Tversky dan Kahneman (1974). Anchoring memengaruhi hasil dari negosiasi gaji (Galinsky \& Mussweiler, 2001), keputusan ekonomi (mis., Simonson \& Drolet, 2004), kalimat kriminal (Englich, Mussweiler, \& Strack, 2006), dan bahkan kemampuan kita untuk memahami hal lainnya (Epley, Keysar, Van Boven, \& Gilovich, 2004). Pada penelitian-penelitian menunjukkan bahwa efek anchoring (mis., Lichtenstein \& Slovic, 1971; Tversky \& Kahneman, 1974; Wilson, Houston, Etling, \& Brekke, 1996) mengacu pada penyesuaian penilaian seseorang. Hal tersebut berdasarkan informasi eksternal sebelumnya atau yang disebut dengan anchoring.

Penelitian ini menunjukkan hasil yang tidak signifikan antara kelompok high anchoring dan low anchoring. Peneliti mengindikasikan adanya pengaruh yang kuat pada instrumen penelitian, yaitu pada rubrik yang terdapat di dalam booklet tiap subjek dalam eksperimen baik kelompok high anchoring maupun low anchoring. Pada rubrik tersebut sudah sangat jelas deskirpsi mengenai kriteria 
penilaian kinerja pegawai. Oleh karena itu, para subjek dalam eksperimen ini tidak terlalu memperhatikan instruksi yang telah diberikan peneliti dimana instruksi tersebut terdapat perlakuan anchoring yang seharusnya menjadi fokus para subjek dalam penelitian ini.

Rubrik digunakan dalam penilaian kinerja agar cara penilaian lebih transparan bagi penilai. Rubrik adalah salah satu assesment yang dapat digunakan untuk mengukur dan menilai secara komprehensif. Rubrik dapat berfungsi sebagai instrumen evaluasi.

Penelitian ini menggunakan rubrik dikarenakan rubrik atau kriteria penilaian kinerja merupakan salah satu bagian penting dalam penilaian kinerja. Rubrik diletakkan pada halaman sebelum penilaian kinerja. Namun hal tersebut justru membuat para subjek menjadi lebih objektif dalam menilai kinerja pegawai yang telah dideskripsikan di dalam booklet. Hal tersebut memungkinkan bahwa para subjek terpapar oleh recency effect. Penelitian menunjukkan bahwa kita cenderung mengingat dengan sangat baik pada bagian akhir dibanding bagian yang lain, ini disebut dengan recency effect (Brunel dan Nelson, 2003). Sehingga pengaruh anchoring atau treatment yang diberikan pada instruksi tidak menjadi perhatian para subjek eksperimen. Maka dari itu, peneliti mengindikasikan perlakuan dengan adanya rubrik dalam penilaian kinerja ini justru yang membuat eksperimen ini tidak berhasil mengisolasi pengaruh anchoring terhadap hasil penilaian kinerja pada aspek task performance.

\section{Kesimpulan}

Kesimpulan dalam penelitian ini adalah anchoring tidak berpengaruh secara signifikan terhadap hasil penilaian kinerja pada aspek task performance disebabkan oleh beberapa faktor yaitu, dalam eksperimen ini tidak terdapat kelompok kontrol, penelitian dilakukan secara klasikal pada kelompok high anchoring dan low anchoring sehingga dapat menyebabkan adanya interaksi antara kedua kelompok eksperimen, serta pengaruh rubrik yang kuat sehingga menyebabkan para subjek eksperimen tidak memperhatikan anchoring yang menjadi treatment dalam penelitian ini.

\section{Saran}

Berdasarkan temuan, pembahasan, dan keterbatasan dalam penelitian ini, peneliti memberikan saran untuk penelitian selanjutnya. Penelitian selanjutnya sebaiknya menggunakan kelompok kontrol agar dapat melihat ada atau tidak perbedaan efek dari anchoring, penelitian selanjutnya sebaiknya melaksanakan eksperimen tidak dengan metode klasikal untuk mengurangi kemudahan para subjek dalam berinteraksi satu sama lain. Selain itu, penelitian selanjutnya sebaiknya meneliti pengaruh dari rubrik untuk menilai hasil penilaian kinerja.

\section{Daftar Pustaka}

Bernardin, John H \& Russell, Joyce A. (1998). Human resource management: An experiental approach. Boston: Mc Graw-Hill.

Brunel, F. F., \& Nelson, M. R. (2003). Message order effects and gender differences in advertising persuasion. Journal of Advertising Research, 43, 330-341. doi: 10.1017/S0021849903030320

Cardy, R. L., \& Dobbins, G. H. (1994). Performance appraisal: Alter-native 
perspectives. Cincinnati: SouthWestern Publishing Company

deLeon, L., \& Ewen, J.A. (1997). Multisource performance appraisals: Employee perceptions of fairness. Re ie of Public Personnel Administration, 17, 22-36. doi: 10.1177/0734371X9701700103

DeNisi, A. S. \& William, K. J. (1998). Cognitive approach to performance appraisal in G Ferris and $\mathrm{K}$. Rowland. Research in Personel and Human Resources Management, 6, 109-155

Dessler, G. (2003). Human resource management. Thirteenth edition. New Jersey: Pearson Prentice Hall.

Englich, B., Mussweiler, T., Strack, F., (2006). Playing dice with criminal sentences: The influence of irrelevant anchors on experts' judicial decision making. Personality and Social Psychology Bulletin, 32(2), 188-200. doi: $\underline{10.1177 / 0146167205282152}$

Epley, N., Keysar, B., Van, Boven, L., Gilovich, T., (2004). Perspective taking as egocentric anchoring and adjustment. Journal of Personality and Social Psychology, 87(3), 327-339. doi: 10.1037/0022-3514.87.3.327

Folger, R., \& Konovsky, M. A. (1989). Effects of procedural and distributive justice on reactions to pay raise decisions. Academy of Management Journal, 32(1), 115-130. doi: $10.2307 / 256422$

Galinsky, A. D., \& Mussweiler, T. (2001). First offers as anchors: The role of perspective-taking and negotiator focus. Journal of Personality and Social Psychology, 81(4), 657-669

Harris, P, L. (1994). The child's understanding of emotion: Developmental change and the family environment. Journal of Child Psychology and Psychiatry, 35(1), 3-28. doi: $\quad$ 10.1111/j.14697610.1994.tb01131.x

Kondrasuk, J. (2011). So what would an ideal performance appraisal look like?. Journal of Applied Business and Economics, 12(1), 57-71

Kreitner, R., \& Kinicki, A. (2011). Organizational behavioral-Ed. 5. Boston: McGraw-Hill.

Lichtenstein, S., \& Slovic, P. (1971). Reversals of preference between bids and choices in gambling decisions. Journal of Experimental Psychology, 89(1), 46-55.

Mangkunegara, A. P. (2003). Perencanaan dan pengembangan sumber daya manusia. Bandung: Refika Aditama.

Murphy, K. R. (1989). Dimensions of job performance. In: Dillon RF, Pellegrino JW, eds. Testing: Theoretical and applied perspectives. New York: Praeger

Riggio, R. E., Riggio, H. R., Salinas, C., \& Cole, E. J. (2003). The role of social and emotional communication skills in leader emergence and effectiveness. Group Dynamics: Theory, Research, and Practice, 7(2), 83-103.

Simonson, I., \& Drolet, A. (2004). Anchoring effects on consumers' willingness-to-pay and willingnessto-accept. Journal of Consumer Research, 31(3), 681-690. doi: $10.1086 / 425103$

Tsui, A., S. \& Ohlott, P. (1988). Multiple assessments of managerial effectiveness: Interrater agreement and consensus in effectiveness models. Pers. Psychol, 41, 779-803. doi: $\underline{10.1111 / \mathrm{j}-1744-}$ 570.1988.tb00654.x 
Tversky, A., \& D. Kahneman. (1974). Judgment under uncertainty: Heuristics and biases. Science, 185(4157), 1124-1131

Werther, W. B., \& Davis, K. (1993). Human resources and personnel management: $\left(4^{\text {the }}\right.$ ), Singapore: McGraw-Hill, Inc.
Wilson, T. D., Houston, C. E., Etling, K. M., \& Brekke, N. (1996). A new look at anchoring effects: basic anchoring and its antecedents. Journal of Experimental Psychology General, 125(4), 387-402. 